\title{
Yükseköğretim sınıflarında iç ortam sıcaklığı ve bağıl nem düzeyinin analizi: Balıkesir Üniversitesi Örneği
}

\author{
Yusuf YILDIZ* \\ Balıkesir Üniversitesi Mimarlık Fak. Mimarlık Böl., Çağış kampüsü, Balıkesir \\ Geliş Tarihi (Received Date): 17.09.2020 \\ Kabul Tarihi (Accepted Date): 23.12.2020
}

$\ddot{O} \mathbf{z}$

Sinıflarda, ögrencilerin bilgiyi algılamasına ve işlemesine yardımcı olmak için konfor koşullarının sağlanması önemli bir ihtiyaçtır. Bu nedenle yapı fiziği açısından doğru bina ve mekan tasarımları gerekmektedir. Aksi takdirde ĕgitim binalarında konforsuz iç mekanlar oluşabilir ve gereksiz enerji tüketimi gerçekleşebilir. Bu çalışma, Balıkesir üniversitesinin doğal olarak havalandırılan beşs sınıfinda iç ortam sıcaklık ve bağll nem değerlerini kullanarak ısıl konforu değerlendirmeyi amaçlamaktadır. Kullanım içi ve dışı saatler dahil olmak üzere parametreler iki aylık süre boyunca 15 dakika aralıklarla kaydedilmiştir. Daha sonra bu veriler excel ve spss programları aracılığlyla istatiksel olarak analiz edilmiş ve uluslarası standartlar ile karşılaştırılmıştır. Elde edilen sonuçlara göre sıcaklık değerleri Şubat ayında ısıtma sistemi nedeniyle genellikle 22$25^{\circ} \mathrm{C}$ aralı̆̆ında seyretmiştir. Mayıs ayında ise iç ortam sicaklıkları çoğunlukla $25^{\circ} \mathrm{C}$ 'nin üzerine çıkmıştır. Bağıl nem değerleri her iki ayda da ASHRAE Standardı 62.1-2007'da önerildiği gibi \%65 sınır değerini önemli ölçüde aşmamaktadır. Ayrıca sınıflar arasında sıcaklık değişimin de anlamlı farkların olduğu bulunmuştur $(p<0.05)$.

Anahtar kelimeler: Akademik binalar, ısıl konfor, iç mekan analizi.

\section{Analysis of indoor temperature and relative humidity level in higher education classes: Balıkesir University Example}

\begin{abstract}
It is an important need that classrooms provide comfortable learning environments to help students perceive and process information. For this reason, correct building and

\footnotetext{
*Yusuf YILDIZ, yusifyildiz@gmail.com.tr, https://orcid.org/0000-0002-3255-6850
} 
space designs are required in terms of building physics. Otherwise, uncomfortable interior spaces and unnecessary energy consumption will occur in educational buildings. This study aims to evaluate thermal comfort by using indoor temperature and relative humidity values in five naturally ventilated classes of Balikesir University. The parameters, including the hours in and out of use, were recorded at 15-minute intervals over a two-month period. Later, these data were analyzed statistically through Excel and SPSS programs and compared with international standards. According to the results, temperature values were generally in the range of $22-25^{\circ} \mathrm{C}$ in February due to the heating system. In May, indoor temperatures mostly exceeded $25^{\circ} \mathrm{C}$. Relative humidity values do not significantly exceed the $65 \%$ limit value every two months, as recommended in ASHRAE Standard 62.1-2007. It was also found that there are significant differences in temperature change between classes $(p<0.05)$.

Keywords: Academic buildings, thermal comfort, indoor condition analysis.

\section{Giriş}

Yükseköğretim tüm ülkeler açısından önemli bir konudur ve nitelikli eğitim için yap1 fiziği açısından kaliteli üniversite binaları önem arz etmektedir. Ülkemiz özelinde ise ilk üniversitenin kurulduğu 1933 yılından günümüze kadar üniversite sayılarında sürekli bir artış gözlenmiştir ve 1982 öncesinde toplam üniversite sayısı 19 iken şu an mevcut üniversite sayısı (Devlet + Vakıf + Vakıf MYO) 207'ye ulaşmıştır. Özellikle eğitim binalarında iç ortam ısıl konfor koşullarının önemi küçümsenemez. Sınıflar öğrenme sürecinde yüksek konsantrasyona uygun mekanlar olmalıdır. Bu tür binalardaki isıl konforsuzluk hem personel hem de öğrenciler için tatmin edici olmayan ortamlar yaratabilir. İnsanlar zamanlarının yaklaşık \%90'ını kapalı alanda geçirdiklerinden, uygun bir iç mekan iklimini sürdürebilmek büyük önem taşımaktadır. Aynı zamanda öğrenciler, günlerinin \%70'ini sınıflarda geçirmekte bu durum sınıfları, öğrenciler için evlerinden sonra en önemli ikinci kapalı alan haline getirmektedir [1,2]. İç mekan ssıl konfor parametrelerinden olan sicaklık ve bağıl nem ayrıca öğrencilerin akademik performansını ve üretkenliğini de etkilemektedir. Bu nedenle eğitim binaları için önemli bir tasarım parametresi olarak kabul edilirler [3-5]. Öğrenme performansının yüksek iç hava sıcaklıklarından etkilendiği de bilinmektedir [6]. Gupta ve ark. [7], çalışma performansı üzerindeki olumsuz etkilerin, ısıtmanın olmadığı sezonda $26^{\circ} \mathrm{C}$ 'nin üzerindeki yüksek sıcaklıklardan kaynaklandığını ifade etmiştir. Okullarda aktif ısıtma sisteminin bulunmasına rağmen soğutma sistemi genellikle bulunmamaktadır. Pencere ve kapıların elle açılıp kapanmasına dayalı doğal havalandırma, özellikle sınıflarda en uygulanabilir ve çok karşılaşılan serinletme ve havalandırma türüdür [8]. Bu nedenlerle iyi tasarlanmış ve bakımı yapılan, ısıl konfor koşullarını sağlayan ve dışarıdan yeterli temiz hava temin eden eğitim binaları, verimli öğrenme süreci ve gelecek nesillerin iyi eğitimi için bir gerekliliktir [9]. Ayrıca, 1sıl olarak yıl boyunca konforlu bir sınıf tasarlamak artık mimarlar ve inşaat mühendisleri için en önemli kriterlerden biri haline gelmiştir [10,11]. Doğal olarak havalandırılan eğitim binalarındaki 1sıl koşulları, konfor standartlarını ve adaptasyonu araştırmak için farklı iklimlerde çeşitli çalışmalar yapılmaktadır [12]. Örneğin Mishra ve Ramgopal [13] tropik iklimde, Zaki ve arkadaşları [14] nemli bir subtropikal ve tropikal yağmurlu iklimde, Singh ve arkadaşları [15] kompozit Hindistan ikliminde, Mustapa ve arkadaşları [16] Japonya tropikal ikliminde, Lopez-Perez ve arkadaşları [17] ise Meksika tropikal sslak ikliminde bulunan doğal havalandırmalı sınıflarda çalışmalar yapmıştır. 
Literatüre bakıldığında 1sıl konforu değerlendirmek için çeşitli uluslararası standartlar olduğu görülmektedir. En bilinenlerinden bir tanesi EN 15251'dir. Ortak bir ölçüm yöntemini tanımlayan EN 15251 [18] standard1, 1sıl, görsel ve akustik konforu göz önünde bulundurarak iç ortam kalitesini karşılamak için bina enerji performansını değerlendirme ve tasarlama kriterlerini içermektedir. ASHRAE Standardi 55 [19], 1sı1 çevre faktörleri ile kişisel faktörlerin kombinasyonlarını özelleştirerek, kullanıcı için ısıl çevre koşulları hakkında kapsamlı genel yönergeler sağlar. Bir diğer uluslararası standartta, kullanıcının ısıl duyusunu (PMV) ve 1sıl memnuniyetsizliğini (PPD) tahmin etmek için yöntemler sunan EN ISO 7730'dur [20]. EN ISO 10551 [10] standardı ise, PMV ve PPD endekslerini değerlendirmek için kullanılacak anket ihtiyacını tanımlar. Daha az bilinen ASHRAE Standardı 62.1 [21] ve Avrupa Standardı CEN CR 1752 [22], binalarda kullanıcı için minimum kabul edilebilir havalandırma oranlarını ve iç hava kalitesini içermektedir.

Bu çalışma, Balıkesir Üniversitesi'nin doğal olarak havalandırılan sınıflarında yürütülen iç mekan sıcaklık ve bağıl nem seviyelerinin şubat ve mayıs aylarında izlenmesinin sonuçlarını bildirmektedir. Bu nedenle, Mühendislik ve Mimarlık Fakültesi binasındaki 5 farklı sınıfta 2019 yılı şubat ve mayıs aylarındaki sıcaklık ve nem koşulları üzerine yapılan bir araştırmanın bulguları sunulmuştur. Sonuçlar istatistiksel olarak analiz edilmiş ve ilgili standartlarla karşılaştırılmıştır. Elde edilen bulgular konforlu ve tek tip olmayan sınıfların uygun şekilde tasarlanmasına yardımcı olabilir.

\section{Yöntem}

Bu çalışma, Balıkesir ilinde bulunan ve 1993 yılında kurulan Balıkesir üniversitesindeki Mühendislik ve Mimarlık Fakültesi (MMF) dersliklerinde gerçekleştirilmiştir. Balıkesir'in uzun süreli iklimsel verilerine bakıldığında, kışları serin, yazları sıcak ve yarı kurak bir iklime sahip olduğu görülmektedir [23].

Çalışma alanı olan Balıkesir Üniversitesi, Çağış Yerleşkesi, Balıkesir-Bigadiç karayolunun 17. km'sinde Çağış ve Paşaköy sınırları içinde yer almaktadır. Çalışma amacıyla Mühendislik ve Mimarlık Fakülteleri tarafından birlikte kullanılan binadan 5 adet derslik seçilmiştir. Kış ve yaz dönemini temsilen Şubat-Mayıs aylarında yapılan yerinde ölçümler ile sıcaklık (Temp) ve bağıl nem (RH) değerleri 15 dakikalık aralıklarla kaydedilmiştir. Ölçüm yapılan sınıflar merkezi kalorifer sistemi kullanılarak 1sıtılmaktadır ve enerji kaynağı doğalgazdır. Bu nedenle sınıflarda sıcaklık ayarı yapılamamaktadır. Sınıflarda soğutma sistemi yoktur. Pencere ve kapıların açılıp kapanmasıyla doğal havalandırma yapılmaktadır.

Mühendislik ve Mimarlık Fakültesi, kuzeybat1-güneydoğu doğrultusunda uzanan dikdörtgen şeklindeki bloklardan oluşmaktadır (Şekil 1). 


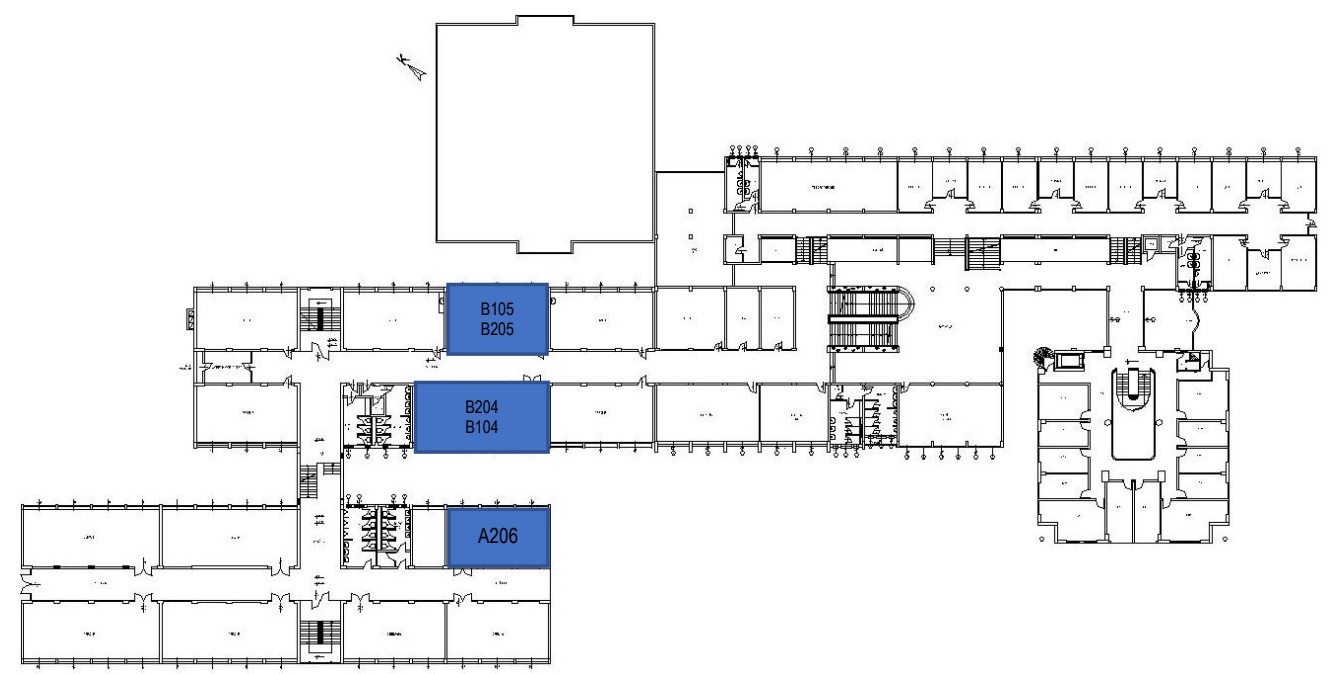

Şekil 1. Müh. ve Mim. Fak. normal kat planı.

Binada, idari ve öğrenci girişi olmak üzere güneybatı yönünde 2 ana giriş bulunmaktadır. Öğrenci alanları, laboratuvarlar, kantin, sınıflar, ofisler vb. dahil olmak üzere çeşitli mekanları barındırmaktadır. Bodrum katta depolar, laboratuvarlar, tesisat merkezi, kantin ve amfi bulunmaktadır. Zemin katta derslik ve laboratuvarlar, akademik ve idari personel odaları ve konferans salonu yer almaktadır. 1. ve 2. katta derslikler, akademik ve idari personel odaları ve seminer odası vardır. 3. katta idari personel odaları, atölyeler ve kütüphane bulunmaktadır. Son olarak 4.5.6. ve 7. katlarda akademik personel odaları devam etmektedir. Farklı blokların farklı kat sayısına sahip olduğu bu binada toplam kapalı alan 20001,25 m²'dir. Bu alanın yaklaşık \%90'1 1sıtılmakta ve \%18'i soğutulmaktadır. Bina yapı elemanlarının toplam isıl geçirgenlik

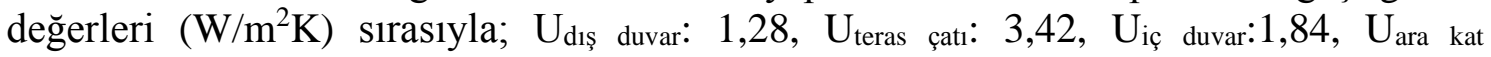
döşeme:2,26, $\mathrm{U}_{\text {taban: }}$ 1,01 ve $\mathrm{U}_{\text {pencere: }}$, 70'tir.

Ölçüm için seçilen tüm sınıflar benzer özelliklere sahiptir (Şekil 2). Sınıf kapasitesi ve kullanım süreleri değişkenlik göstermektedir ve bu durum Tablo 1'de özetlenmiştir.

Tablo 1. Çalışılan dersliklerin özellikleri.

\begin{tabular}{|c|c|c|c|c|c|c|c|c|c|}
\hline Bina & Sinıf & Kat & $\begin{array}{c}\text { Pencere } \\
\text { sayısı }\end{array}$ & $\begin{array}{c}\text { Pencere } \\
\text { alanı }\left(\mathbf{m}^{2}\right)\end{array}$ & $\begin{array}{l}\text { Kapı } \\
\text { sayısı }\end{array}$ & $\begin{array}{c}\text { Sinıf } \\
\text { alanı } \\
\left(\mathrm{m}^{2}\right)\end{array}$ & $\begin{array}{c}\text { Kişi } \\
\text { kapasitesi }\end{array}$ & $\begin{array}{c}\text { Gün boyu } \\
\text { kullanım } \\
\text { süresi }\end{array}$ & Yön \\
\hline \multirow{5}{*}{$\mathrm{MMF}$} & a206 & 2 & 1 & 26,64 & 1 & 102 & 120 & \multirow{5}{*}{$\begin{array}{l}\text { 09:00 a.m.- } \\
\text { 17:00 p.m. }\end{array}$} & KD \\
\hline & b104 & 1 & 1 & 26,64 & 1 & 100 & 112 & & GB \\
\hline & b204 & 2 & 1 & 26,64 & 1 & 100 & 112 & & GB \\
\hline & b105 & 1 & 1 & 19,98 & 1 & 81 & 72 & & KD \\
\hline & b205 & 2 & 1 & 19,98 & 1 & 81 & 72 & & KD \\
\hline
\end{tabular}




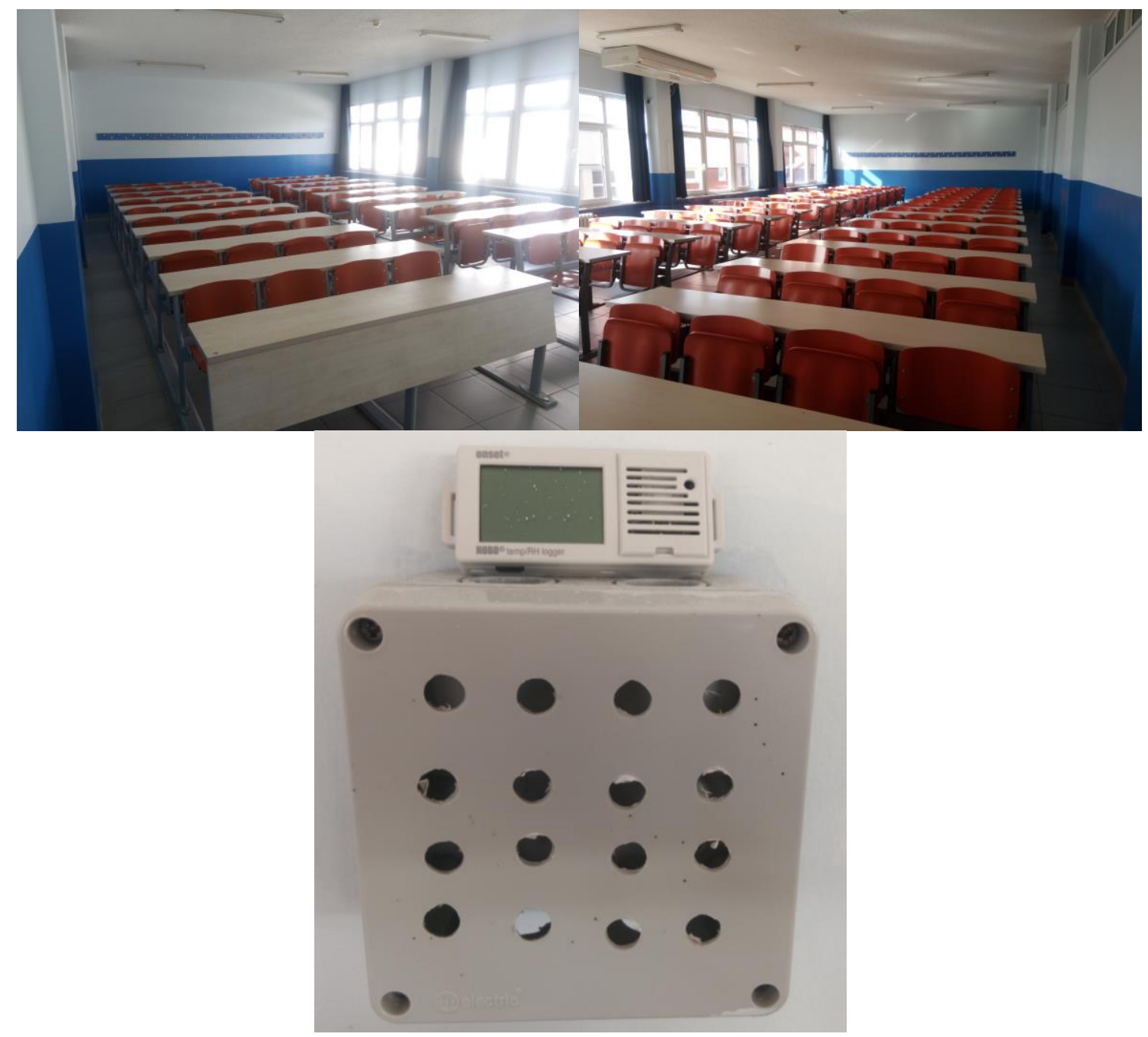

Şekil 2. Ölçüm yapılan 1sınıflardan örnekler ve ölçüm cihazı.

İki parametrenin (RH ve Temp) izlenmesi için Hobo veri kaydedici (Bağıl nem ölçüm aralığı: \%15-\%95, Doğruluk: \% \pm 3.5 , Çözünürlük: \% 0.07; Sıcaklık ölçüm aralığı: $20^{\circ} \mathrm{C}-+70^{\circ} \mathrm{C}$, Doğruluk : $\pm 0.21^{\circ} \mathrm{C}$, Çözünürlük : $0.024^{\circ} \mathrm{C}$ ) kullanılmıştır (Şekil 2). Ölçümler 15 dakikalık aralıklarla sürekli olarak yapılmıştır. Cihazlar duvarlara yerden yaklaşık 1,5 m yükseklikte, pencerelerden, doğrudan güneş ışığından ve 1sıtma cihazlarından uzağa monte edilmiştir. Kayıt cihazı hafizasının dolması sebebiyle bazı zamanlar kısa süreli veri kayıpları yaşanmıştır. Dış hava sıcaklık ve nem ölçümleri yine Hobo veri kaydedici (Bağıl nem ölçüm aralığı: \%0-\%100, Hassasiyet: \%2.5, Çözünürlük: \% 0.03; Sicaklık ölçüm aralığı: $-40^{\circ} \mathrm{C}-+70^{\circ} \mathrm{C}$, Hassasiyet: $0.18^{\circ} \mathrm{C}$, Çözünürlük: $0.02^{\circ} \mathrm{C}$ ) ile yapılmıştır.

Ham sıcaklık ve bağıl nem verileri Microsoft Excel 2016'ya girilmiştir ve ardından istatistiksel analizlerin yanı sıra anormallikleri ve eksik değerleri kontrol etmek için SPSS 21 istatistiksel hesaplama yazılımına aktarılmıştır. Ölçülen değerlerde sınıflar arasında anlamlı bir fark olup olmadığı parametrik olmayan Wilcoxon İşaretli Sıralar Testi kullanılarak analiz edilmiştir. Bu test, ilişkili iki ölçüm setine ait puanlar arasındaki farkın anlamlı olup olmadığını kontrol etmek için kullanılır. 


\section{Bulgular ve tartışma}

\subsection{Sicaklık ve bă̆ıl nem değerleri}

Sınıflara ve dış ortama ait 2019 yılı Şubat ve Mayıs ayı sıcaklık ve bağıl nemdeki değişim trendi Şekil 3 de gösterilmiştir. Ayrıca Tablo 2 de sıcaklık ve bağıl nem değerleri için tanımlayıcı istatistiksel parametreler özetlenmiştir. Dış ortam koşulları, odaların yönü, kişi yoğunluğu ve HVAC sistem türü dahil olmak üzere birçok faktörün, sıcaklık ve bağıl nemdeki değişimi etkilediği bilinmektedir [7]. Şubat ayı sıcaklık trendine bakıldığında iç ortam sıcaklıkları çoğunlukla $20-25^{\circ} \mathrm{C}$ aralığında seyretmektedir. Sicaklıkların belirli bir aralıkta seyretmesinin nedeni iç ortamın aktif bir sistemle 1sıtılmasıdır. Bağıl nem değerleri ise daha fazla değişkenlik göstermektedir. Mayıs ayında ise sınıflarda zaman zaman iç sıcaklık değerlerinin dış sıcaklık değerleri ile çakıştığı, bazen ise $30^{\circ} \mathrm{C}$ 'nin üzerine çıktığ 1 görülmektedir. $\mathrm{Bu}$ durum bina dış kabuğunun istenen 1sıl direnci her zaman ve yeterli düzeyde sağlayamadığının bir işaretidir. Bağıl nem değerleri ise Şubat ayında olduğu gibi çok fazla değişkenlik göstermektedir.

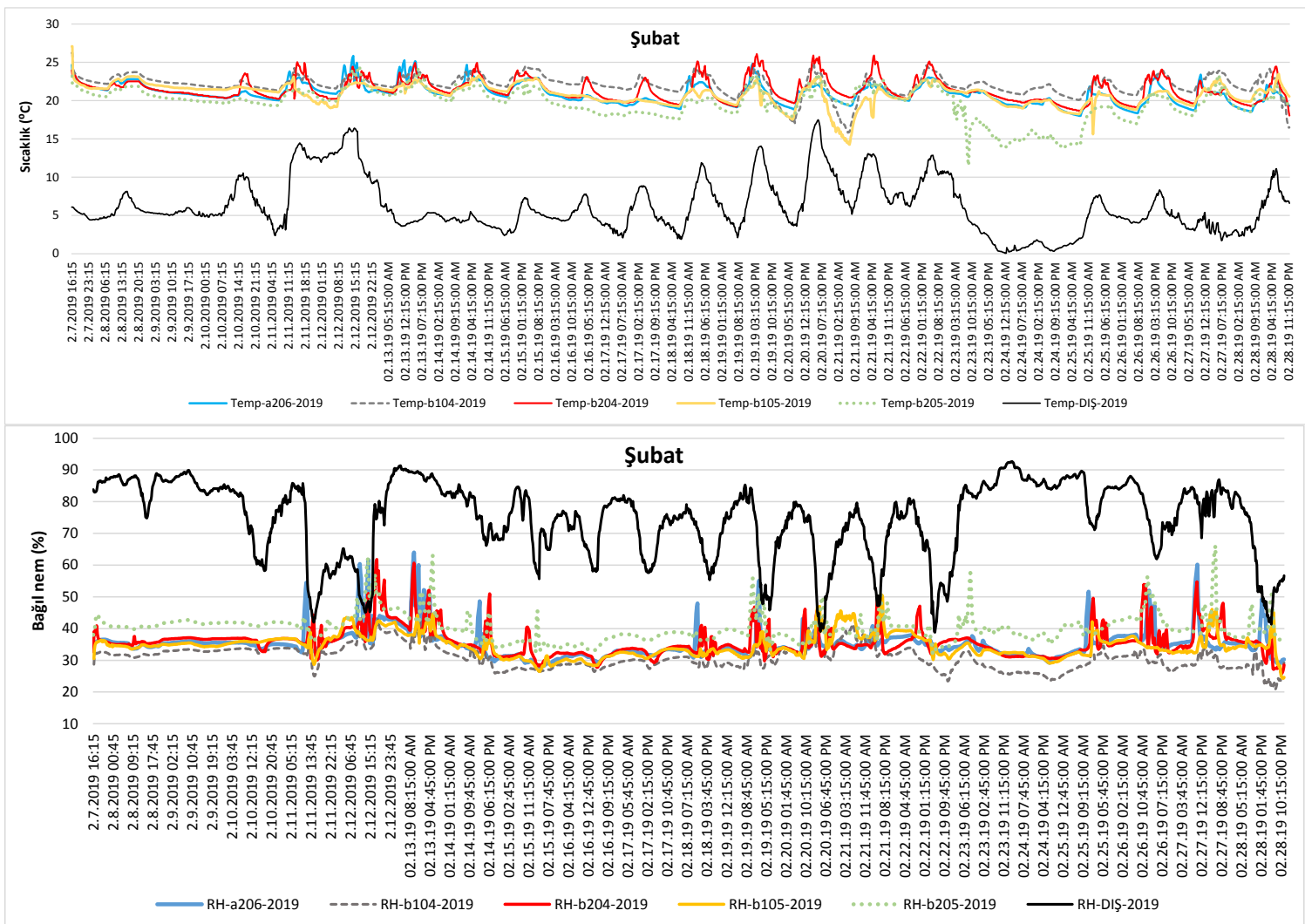

Şekil 3. Şubat ve mayıs ayı sıcaklık ve bağıl nem trendi. 


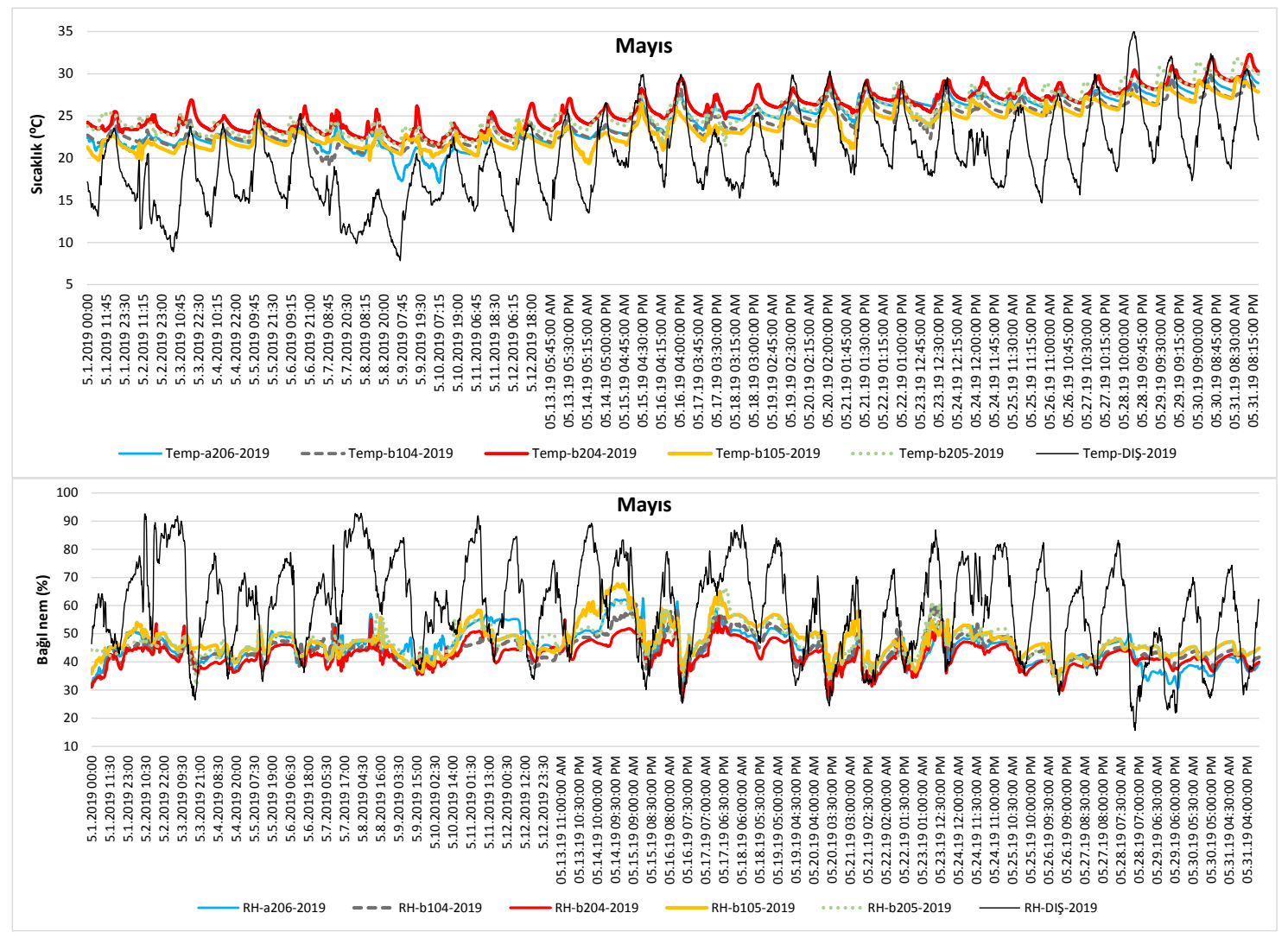

Şekil 3 (Devam). Şubat ve mayıs ayı sıcaklık ve bağıl nem trendi.

Ölçümlerin yapıldı $\breve{g}_{1}$ periyotta şubat ayı ortalama dış hava sıcaklığ $6,1^{\circ} \mathrm{C}$ (min: 0,06 ve maks: $17,49^{\circ} \mathrm{C}$ ) dir (Tablo 2). Mayıs ayında ise ortalama dıș hava sıcaklığı $24,62^{\circ} \mathrm{C}$ (min: 7,85 ve maks: $35^{\circ} \mathrm{C}$ ) olarak kaydedilmiştir. a206, b104, b204, b105, b205 nolu sınıflarda gözlemlenen şubat ayı ortalama sıcaklık değerleri sırasıyla $20,90^{\circ} \mathrm{C}, 22,05^{\circ} \mathrm{C}$, $21,39^{\circ} \mathrm{C}, 20,81^{\circ} \mathrm{C}$ ve $19,73^{\circ} \mathrm{C}$ 'dir. Gözlemlenen maksimum değerler $25,85^{\circ} \mathrm{C}, 26,24^{\circ} \mathrm{C}$, $26,10^{\circ} \mathrm{C}, 27,29^{\circ} \mathrm{C}$ ve $24,26^{\circ} \mathrm{C}$ iken minimum değerler sirasiyla $18,01^{\circ} \mathrm{C}, 15,82^{\circ} \mathrm{C}$, $18,05^{\circ} \mathrm{C}, 14,24^{\circ} \mathrm{C}$ ve $11,53^{\circ} \mathrm{C}$ 'dir. Yaz dönemi için sınıflarda aktif soğutma sistemi bulunmamaktadir. Mayis ayında a206, b104, b204, b105, b205 nolu siniflarda gözlemlenen ortalama sicaklık değerleri sirasıyla $24,45^{\circ} \mathrm{C}, 24,17^{\circ} \mathrm{C}, 25,80^{\circ} \mathrm{C}, 23,70^{\circ} \mathrm{C}$, $25,43^{\circ} \mathrm{C}$ 'dir. Ölçülen maksimum değerler $30^{\circ} \mathrm{C}, 30,30^{\circ} \mathrm{C}, 32,29^{\circ} \mathrm{C}, 29,55^{\circ} \mathrm{C}, 31,88^{\circ} \mathrm{C}$ iken minimum değerler sirasıyla $17,06^{\circ} \mathrm{C}, 19,25^{\circ} \mathrm{C}, 21,28^{\circ} \mathrm{C}, 19,35^{\circ} \mathrm{C}, 21,38^{\circ} \mathrm{C}$ 'dir.

Örneklem dönemi boyunca şubat ve mayıs ayı ortalama dış ortam bağıl nem seviyesi $\% 74,8$ ve $\% 59,22$ olarak kaydedilmiştir (şubat min: $\% 38,82$ ve maks: $\% 92,69$, mayıs min: \% 15,70 ve maks: \%92,75). a206, b104, b204, b105, b205 nolu sinıflarda şubat ay1 ortalama değerleri sirasiyla \%35,18, \%30,83, \%35,67, \%34,58, \%40,17'dir. Gözlemlenen maksimum nem seviyeleri \%63,99, \%42,87, \%61,76, \%50,55, \%66,24 iken minimum seviyeler sirasiyla \%27,73, \%20,80, \%25,91, \%24,31, \%32,39'dir. May1s ayında ölçülen maksimum bağıl nem değerleri ise sirasıyla \%62,61, \%61,13, \%56,35, $\% 67,76, \% 65,74$ iken minimum değerler \%26,95, \%25,62, \%27,42, \%32,63 ve $\% 31,66$ 'dir.

Şubat ayında sıcaklıktaki standart sapma değerlerine bakıldığında b205 nolu sınıfta diğer sınıflara göre daha fazla değişkenlik vardır. b205 nolu sınıf haricindeki diğer sınıflarda ise birbirine yakın değerler elde edilmiştir. Bağıl nem değerleri açısından 
görece en fazla değişkenlik b204 nolu sınıfta gerçekleşmiştir. Mayıs ayında ise sıcaklık değerleri açısından birbirine benzer standart sapma değerleri görülmektedir. Buradaki dikkat çekici nokta sınıflardaki sıcaklıklar dış ortam sıcaklık değişimine yakın derecede değişkenlik göstermiştir. Bu durum iç ortam sıcaklıklarının hızlı bir şekilde dış koşullardan etkilendiğini göstermektedir. Bağıl nem değerleri açısından a206 nolu sınıf için en büyük standart sapma değeri elde edilmiştir.

Tablo 2. Şubat-Mayıs ayı sıcaklık $\left({ }^{0} \mathrm{C}\right)$ ve bağıl nem (\%) için tanımlayıcı istatistiksel parametreler.

\begin{tabular}{|c|c|c|c|c|c|}
\hline \multicolumn{6}{|c|}{ Şubat ayı sıcaklıkları } \\
\hline Derslikler & Ortalama & Min. & Max. & Standart sapma & Ölçüm sayısı \\
\hline a206 & 20,90 & 18,01 & 25,85 & 1,31 & \multirow{6}{*}{2047} \\
\hline b104 & 22,05 & 15,82 & 26,24 & 1,29 & \\
\hline b204 & 21,39 & 18,05 & 26,10 & 1,41 & \\
\hline b105 & 20,81 & 14,24 & 27,09 & 1,38 & \\
\hline b205 & 19,73 & 11,53 & 24,26 & 2,02 & \\
\hline Dış & 6,1 & 0,06 & 17,49 & 3,47 & \\
\hline \multicolumn{6}{|c|}{ Şubat ayı bağıl nem değerleri } \\
\hline a206 & 35,18 & 27,73 & 63,99 & 4,42 & \multirow{6}{*}{2047} \\
\hline b104 & 30,83 & 20,80 & 42,87 & 3,57 & \\
\hline b204 & 35,67 & 25,91 & 61,76 & 4,43 & \\
\hline b105 & 34,58 & 24,31 & 50,55 & 3,60 & \\
\hline b205 & 40,17 & 32,39 & 66,24 & 4,15 & \\
\hline Dış & 74,80 & 38,82 & 92,69 & 12,04 & \\
\hline \multicolumn{6}{|c|}{ Mayıs ayı sıcaklıkları } \\
\hline a206 & 24,45 & 17,06 & 30 & 2,79 & \multirow{6}{*}{2976} \\
\hline b104 & 24,17 & 19,25 & 30,30 & 2,21 & \\
\hline b204 & 25,80 & 21,28 & 32,29 & 2,31 & \\
\hline b105 & 23,70 & 19,35 & 29,55 & 2,30 & \\
\hline b205 & 25,43 & 21,38 & 31,88 & 2,40 & \\
\hline Dış & 24,62 & 7,85 & 35 & 2,87 & \\
\hline \multicolumn{6}{|c|}{ Mayıs ayı bağıl nem değerleri } \\
\hline a206 & 44,80 & 26,95 & 62,61 & 6,25 & \multirow{6}{*}{2976} \\
\hline b104 & 44,31 & 25,62 & 61,13 & 5,23 & \\
\hline b204 & 42,50 & 27,42 & 56,35 & 4,53 & \\
\hline b105 & 47,43 & 32,63 & 67,76 & 5,88 & \\
\hline b205 & 46,78 & 31,66 & 65,74 & 5,27 & \\
\hline Diș & 59,22 & 15,70 & 92,75 & 16,39 & \\
\hline
\end{tabular}

Sınıflar arasındaki farklılıkları daha iyi analiz edebilmek için şubat ve mayıs ayı en sıcak günlerine ait 24 saatlik ölçüm sonuçları Şekil 4 de verilmiştir. 


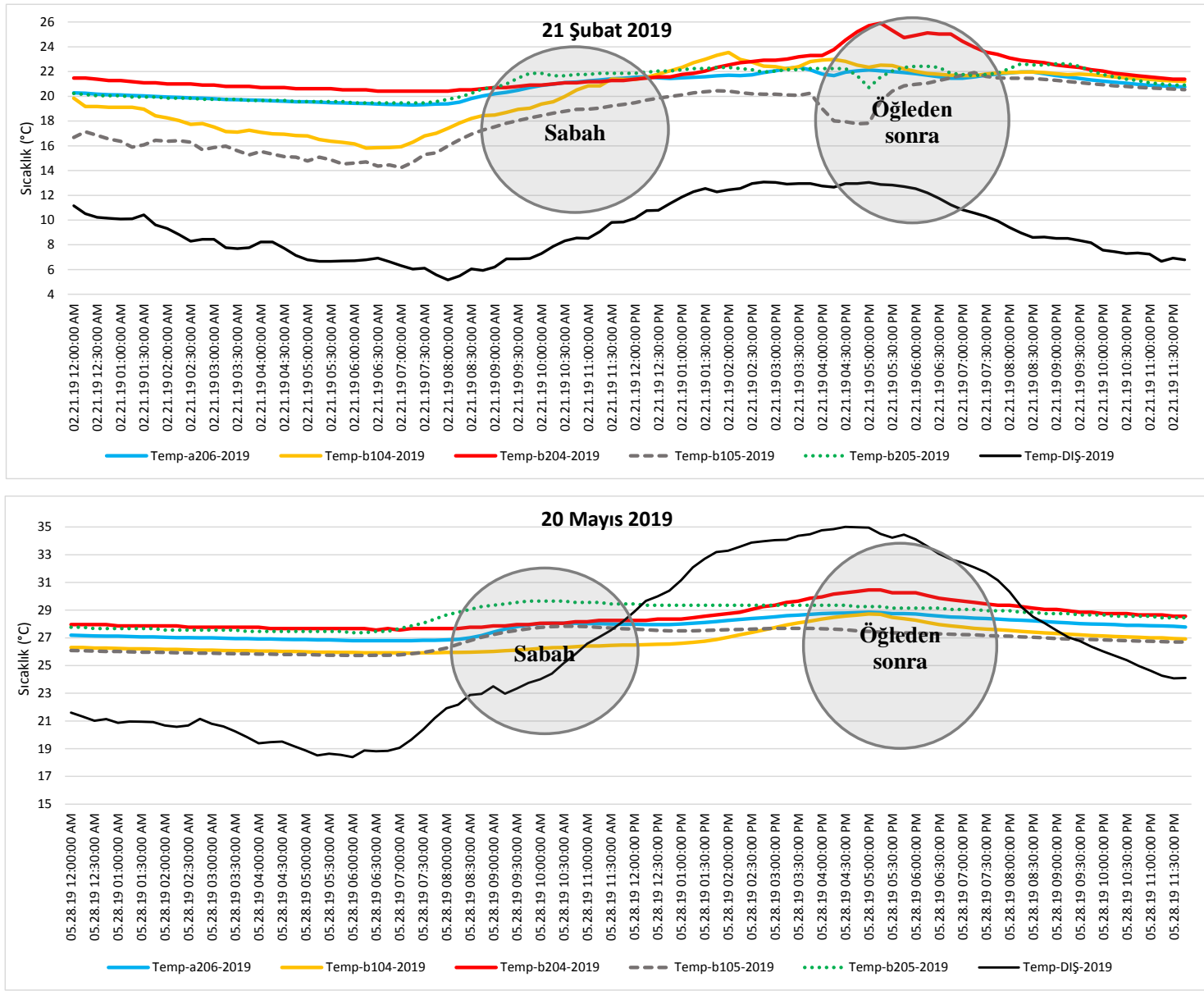

Şekil 4. Sınıfların en sıcak gün için 24 saatlik sıcaklık profili.

b205 ve b105 nolu sınıflar doğuya yöneliminden dolayı sabah saatlerinde direk güneş 1şınlarına maruz kalmaktadır. Özellikle b205 nolu sınıfta Şubat ayında sabah saatlerinde güneş 1şınları kaynaklı iç ortam sıcaklığındaki artış eğilimi net bir şekilde görülmektedir. Ayrıca bu saatlerde b205 nolu sınıfta diğer sınıflara göre daha yüksek ortalama sıcaklık değerleri kaydedilmiştir. Fakat aynı yöne bakan ve bir alt katta bulunan b105 nolu sınıfta aynı saatlerde b205 nolu sınıfa göre daha düşük sıcaklıklar ölçülmüştür. Aradaki fark $2^{\circ} \mathrm{C}$ 'nin üzerine çıkmaktadır. Bu iki sınıfın yaklaşık $6 \mathrm{~m}$ ilerisinde amfi bloğu yer almaktadır. Bu binanın, özellikle 1. kattaki b105 nolu sınıfa ulaşacak gün ışığını önemli ölçüde azalttığı tahmin edilmektedir. Bu durum alt kattaki sınıfta sabah saatlerinde daha düşük sıcaklıkların kaydedilmesini açıklamaktadır. Özellikle yaz aylarında gölgeleme etkisinin iç ortam konforunu pozitif yönde etkileyeceğinin de bir göstergesidir. Bir diğer önemli nokta ise alt kattaki sınıflarda üst kattaki sınıflara göre görece daha düşük iç ortam sıcaklıklarının kaydedilmesidir. Muhtemel sebepleri arasında gölgeleme etkisi ve ısınan havanın yükselmesi prensibi sayılabilir. $\mathrm{Bu}$ durum yaz aylarında avantajlı iken kış aylarında ise dezavantaj oluşturmaktadır. Batı yönüne bakan sınıflarda ise güneş 1şınlarının öğleden sonra görece yataya yakın açıda gelmesi nedeniyle iç ortama daha fazla nüfuz etmektedir ve bu sınıflarda iç ortam sıcaklıkları daha yüksek seyretmektedir. b204 nolu sınıfta öğleden sonra en yüksek iç ortam sıcaklıkları kaydedilmiştir. Mayıs ayında, akşam ve gece saatlerinde sinıflardaki sicaklıkların $26-28^{\circ} \mathrm{C}$ mertebelerinde sabit bir seyir izlediği görülmektedir. $\mathrm{Bu}$ durum binanın kullanılmadığı zamanlarda dış hava sıcaklığının düşmesine rağmen iç ortamın yeteri kadar soğuyamadığını göstermektedir. Aynı 
zamanda doğal havalandırmanın yetersizliğine işaret etmektedir. Binanın dış hava sıcaklığının düşük olduğu saatlerde doğal havalandırma yoluyla gece soğutması yapılması binanın kullanılmaya başlandığı sabah saatlerinde daha konforlu sınıflar elde edilmesine katkı sağlayabilir.

Histogramlar genel anlamda, verilerin ortalamasını, dağılımını (yayılmasını) ve şeklini (göreceli sıklığını) göstermek için tasarlanmış bir veri dağılım grafikleridir. Histogramlar, tablo veya diğer biçimlerde anlaşılması zor olan büyük miktarda verinin görsel bir görüntüsünü verebilir. Bu nedenle şubat ve mayıs ayı boyunca 15 dakikalık aralıklarla yapılan sıcaklık ölçümlerinden elde edilen veriler ile histogram grafikleri oluşturulmuş ve Şekil 5 de gösterilmiştir. Her sınıfta farklılıkların olduğu görülmektedir. Genellikle normal dağılım sergilemektedir. Şubat ayına bakıldığında aktif ısıtma dönemi olduğu için sınıflarda sıcaklıklar tek pik noktalı ve sıklıkla $20-22^{\circ} \mathrm{C}$ arasında gerçekleşmiştir. Dar bir aralıkta sıcaklıkların tekrar etmesinin nedeni sınıfların 1sitılmasidır. b205 nolu sinıfta çok az siklıkta olsa da sicaklıklar $15^{\circ} \mathrm{C}$ 'nin altında seyretmiştir. Mayıs ayında aktif bir soğutma sistemi olmaması nedeniyle çok farklı sıklıkta farklı sıcaklıklar kaydedilmiştir. $25^{\circ} \mathrm{C}$ 'nin üzerindeki sıcaklıklar tüm sınıflarda çoğunlukla ölçülmüştür. Ayrıca $25^{\circ} \mathrm{C}$ 'nin altında ve üzerinde olmak üzere 2 pik noktası görülmektedir.
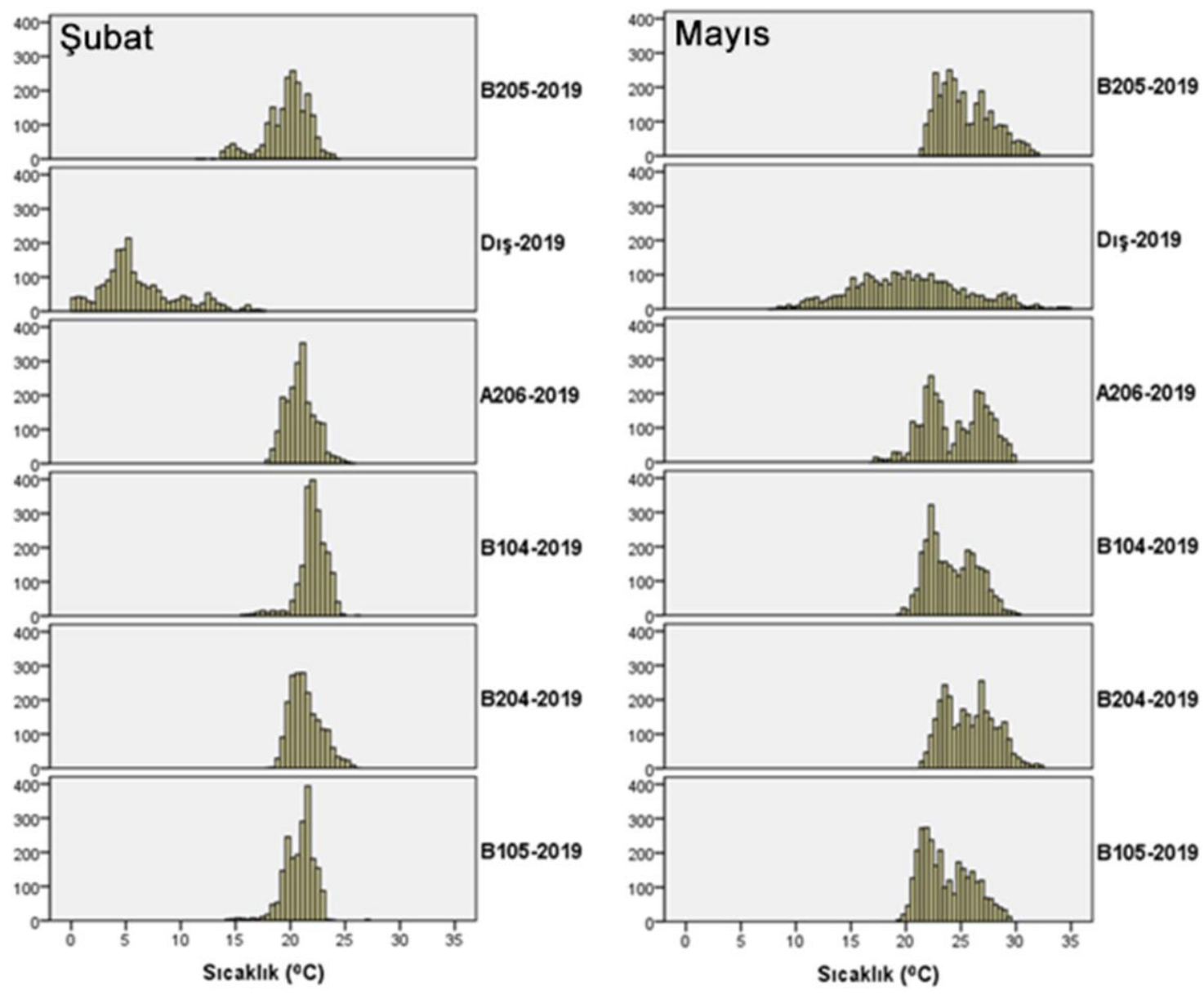

Şekil 5. Şubat ve mayıs ayı sıcaklık ölçüm verilerinin histogram analizi.

Şubat ve Mayıs ayında ölçülen değerlerde, sınıflar arasında anlamlı bir fark olup olmadığı parametrik olmayan Wilcoxon İşaretli Suralar Testi kullanılarak 
değerlendirilmiştir. Elde edilen sonuçlara göre Şubat ayında sadece a206 ile b105 sınıfında ölçülen sıcaklıklar arasında anlamlı bir farkın olmadığı bulunmuştur $(\mathrm{p}>0,05)$. Mayıs ayında ise her sınıfta anlamlı farklılık olduğu tespit edilmiştir $(p<0,05)$. Bağıl nem açısından ise anlamlı farklılık olmayan sınıf yoktur.

\subsection{Sıcaklık ve bă̆ıl nem dĕgerlerinin ASHRAE Standardına göre değerlendirilmesi}

ASHRAE Standardı 62.1-2007'ye göre, bağıl nem \%65'in altında tutulmalıdır [21]. Benzer şekilde, ASHRAE Standard1 55-2010'e göre, 1sıl konfor için sıcaklıklar 22,5 ile $25,5^{\circ} \mathrm{C}$ arasında değişebilir [19]. Tablo 3, ölçülen sıcaklık ve bağıl nem değerlerinin yukarıda ifade edilen değerlerden yüzde olarak aşımını göstermektedir.

Tablo 3. Sicaklık ve bağıl nem değerleri için ASHRAE Standartlarının aşılması (\%).

\begin{tabular}{|c|c|c|c|c|c|}
\hline & \multicolumn{3}{|c|}{ Subat } & \multicolumn{2}{|c|}{ Mayıs } \\
\hline & Sicaklık & & Bağıl nem & Sicaklık & Bağıl nem \\
\hline Sinıflar & $<22,5$ & $>25,5$ & $>\% 65$ & $>25,5$ & $>\% 65$ \\
\hline a206 & $\begin{array}{l}\text { 37,1 (Eğitim- } \\
\text { öğretim dişı) } \\
\text { 1,1 (Eğitim-öğretim } \\
\text { zamanları) }\end{array}$ & 0,09 & 0 & $\begin{array}{c}41,8 \\
\text { (Eğitim- } \\
\text { öğretim } \\
\text { zamanları) }\end{array}$ & 0 \\
\hline b104 & $\begin{array}{l}15,9 \text { (Ĕ̆itim- } \\
\text { öğretim dişı) } \\
\text { 1,2 (Eğitim-öğretim } \\
\text { zamanları) }\end{array}$ & 0,09 & 0 & $\begin{array}{c}32,3 \\
\text { (Eğitim- } \\
\text { öğretim } \\
\text { zamanları) }\end{array}$ & 0 \\
\hline b204 & $\begin{array}{l}27,5 \text { (Eğitim- } \\
\text { öğretim dişı) } \\
1,01 \text { (Eğitim- } \\
\text { öğretim zamanları) }\end{array}$ & 0,48 & 0 & $\begin{array}{c}53,7 \\
\text { (Eğitim- } \\
\text { öğretim } \\
\text { zamanları) }\end{array}$ & 0 \\
\hline b105 & $\begin{array}{l}\text { 41,1 (Eğitim- } \\
\text { öğretim diş1) } \\
\text { 1,3 (Eğitim-öğretim } \\
\text { zamanları) }\end{array}$ & 0,09 & 0 & $\begin{array}{c}25,6 \\
\text { (Eğitim- } \\
\text { öğretim } \\
\text { zamanları) }\end{array}$ & 1,5 \\
\hline b205 & $\begin{array}{l}\text { 45,4 (Ĕ̆itim- } \\
\text { öğretim dış1) } \\
1,11 \text { (Eğitim- } \\
\text { öğretim zamanları) }\end{array}$ & 0,09 & 1 & $\begin{array}{c}42,9 \\
\text { (Eğitim- } \\
\text { öğretim } \\
\text { zamanları) }\end{array}$ & 0,13 \\
\hline
\end{tabular}

Ölçümler boyunca şubat ayı içinde sınıflarda sıcaklık seviyesi $22,5^{\circ} \mathrm{C}$ 'nin altına $\% 1$ mertebelerinde düşmüştür. $22,5{ }^{\circ} \mathrm{C}^{\prime}$ nin altına düştüğü zamanların çoğunlukla eğitimöğretimin yapılmadığı zamanlar olduğu görülmüsstür. Kış döneminde eğitim-öğretim zamanlarında sınıflardaki iç sıcaklıkların $25,5^{\circ} \mathrm{C}$ 'nin üzerine çıkması aktif 1 sıtma sisteminin çok nadir olsa da ihtiyaçtan daha fazla 1sıl kapasitede çalıştırıldığ anlamına gelmektedir. $\mathrm{Bu}$ durum enerji tüketimini gereksiz şekilde arttırabilir. Bağıl nem değerleri ise tüm sınıflarda standardta öngörülen değerler mertebesindedir. Mayıs ayına bakıldığında doğal havalandırmalı b204 nolu sınıfta eğitim-öğretim zamanının $\% 53,7^{\prime}$ inde sicaklıkların $25,5^{\circ} \mathrm{C}$ 'nin üstünde olduğu görülmektedir. a206 ve b205 nolu sınıflarda ise bu oran \%40'ın üzerindedir. Mayıs ayı içinde görece en iyi 1sıl konfor şartlarına sahip sınıflar ise b104 ve b105 nolu sınıflardır. Bir diğer ilginç nokta ise ölçüm yapılan zaman zarfında sınıfların kullanıldığı dönemin sadece \%16'sında dışarıdaki sıcaklıklar $25,5^{\circ} \mathrm{C}$ 'nin üzerine çıkmıştır. Bu nedenle sınıflardaki iç 
sıcaklıkların dışarıdaki hava sıcaklığından zaman zaman daha yüksek olduğu söylenebilir. Sıcak hava sınıflarda birikmektedir ve dış hava sıcaklığı düşmesine rağmen iç sıcaklıklar düşmemektedir. Sınıflarda doğal havalandırmanın çoğunlukla yetersiz olduğu söylenebilir. Ayrıca bu durum binanın yetersiz yalıtıldığını, pencerelerde kullanılan camların doğru seçilmediği ve bu nedenle dış iklim koşullarının iç mekan isıl koşullarını kolaylıkla etkilediğini göstermektedir. Bağıl nem açısından sınıflarda herhangi bir önemli problem yoktur. Alt kattaki sınıflarda üst kattaki sinıflara göre isıl konforun daha iyi düzeyde olduğu görülmektedir.

\section{Sonuçlar}

Çalışmada, Balıkesir Üniversitesi, Mühendislik ve Mimarlık Fakültesi binasının doğal havalandırmalı sınıflarında sıcaklık ve bağıl nem değerlerinin izlenmesiyle isıl konfor durumunun değerlendirilmesi sunulmuştur. Aynı bina içinde aynı koşullara maruz kalan nerdeyse tüm sınıflarda ölçülen değerlerin istatistiksel olarak anlamlı bir şekilde farklılaştığı tespit edilmiştir. Ayrıca elde edilen bulguların analizinden bazı temel sonuçlar çıkarılmıştır:

- Isıl konfor koşullarının diş ortam iklim durumu yanında sınıfların yönelimi ile de ilişkili olduğu görülmüştür. Doğuya bakan sınıflarda sabah saatlerinde batıya bakan sınıflarda ise öğleden sonra iç sıcaklıklarda bir artış gözlenmiştir.

- Güneş ışınlarının iç ortama ulaşmasını güçleştiren faktörlerin varlığına oldukça dikkat edilmelidir. Kış ve yaz durumu için ayrı analizler yapılarak optimum çözümler aranmalıdır.

- Bağıl nem değerleri her iki ayda da ASHRAE Standard1 62.1-2007'da önerildiği gibi \%65 sınır değerini önemli ölçüde aşmamaktadır. Sıcaklık değerleri ise şubat ayında gün içinde çoğunlukla $22-25^{\circ} \mathrm{C}$ aralığında seyretmektedir. Çok küçük bir zaman aralığında sıcaklıkların üst eşik değerini geçtiği görülmüştür. Bu durum binada gereksiz enerji tüketiminin olduğunu göstermektedir. Mayıs ayında ise 1sıl konfor dış ortam sıcaklık değerlerinden etkilenerek, iç ortam sıcaklık değerleri sınıflarda yüksek seyretmiş ve çoğunlukla standartların dışına çıkılmıştır.

- Aynı koşullara maruz kalan sınıflarda iç mekan sıcaklıkları anlamlı ölçüde (p $<0.05$ ) farkl1lık göstermektedir.

Öğrencilerin sağlık güvenliğini ve daha iyi öğrenme performansını sağlamak, optimum düzeyde enerji tüketimini ve yeterli ısıl konfor seviyesini korumak için bina tasarım aşamasında, özellikle mekansal organizasyon yapılırken oryantasyonun, malzeme seçimi, çevredeki durumun, katlar içindeki yerleşimin, yalıtımın, gece soğutması potansiyelinin gereken şekilde analiz edilerek dikkate alınması tavsiye edilir.

\section{Kaynaklar}

[1] Majd, E., McCormack, M., Davis, M., Curriero, F., Berman, J., Connolly, F., Leaf, P., Rule, A., Green, T., Clemons-Erby, D., Gummerson, C. ve Koehler, K., Indoor air quality in inner-city schools and its associations with building characteristics and environmental factors, Environmental Research, 170, 8391, (2019).

[2] Bakó-Biró, Z., Clements-Croome, D.J., Kochhar, N., Awbi, H.B. ve Williams, 
M.J., Ventilation rates in schools and pupils' performance, Building and Environment, 48, 215-223, (2012).

[3] Che, W.W., Tso, C.Y., Sun, L., Ip, D.Y.K., Lee, H., Chao, C.Y.H. ve Lau, A.K.H., Energy consumption, indoor thermal comfort and air quality in a commercial office with retrofitted heat, ventilation and air conditioning (HVAC) system, Energy and Buildings, 201, 202-215, (2019).

[4] Heracleous, C. ve Michael, A., Experimental assessment of the impact of natural ventilation on indoor air quality and thermal comfort conditions of educational buildings in the Eastern Mediterranean region during the heating period, Journal of Building Engineering, 26, 100917, (2019).

[5] de Abreu-Harbich, L.V., Chaves, V.L.A. ve Brandstetter, M.C.G.O., Evaluation of strategies that improve the thermal comfort and energy saving of a classroom of an institutional building in a tropical climate, Building and Environment, 135, 257-268, (2018).

[6] Teli, D., Bourikas, L., James, P.A.B. ve Bahaj, A.S., Thermal performance evaluation of school buildings using a children-based adaptive comfort model, Procedia Environmental Sciences, 38, 844-851, (2017).

[7] Gupta Rajat, A.H. C.T. ve John, O'Brien., Improving productivity in the workplace -lessons learnt and insights from the whole life performance plus project,

http://www.bco.org.uk/Research/Publications/Improving_Productivity_in_the_W orkplace.aspx, (05.09.2020).

[8] Duarte, R., Glória Gomes, M. ve Moret Rodrigues, A., Estimating ventilation rates in a window-aired room using Kalman filtering and considering uncertain measurements of occupancy and $\mathrm{CO} 2$ concentration, Building and Environment, 143, 691-700, (2018).

[9] M. Griffiths ve M. Eftekhari, Control of $\mathrm{CO} 2$ in a naturally ventilated classroom, Energy and Buildings, 40, 556-560, (2008).

[10] Nguyen, A.T., Singh, M.K. ve Reiter, S., An adaptive thermal comfort model for hot humid South-East Asia, Building and Environment, 56, 291-300, (2012).

[11] Corgnati, S.P., Filippi, M. ve Viazzo, S., Perception of the thermal environment in high school and university classrooms: Subjective preferences and thermal comfort, Building and Environment, 42, 951-959, (2007).

[12] Sarbu, I. ve Pacurar, C., Experimental and numerical research to assess indoor environment quality and schoolwork performance in university classrooms, Building and Environment, 93, 141-154, (2015).

[13] Mishra, A.K. ve Ramgopal, M., A thermal comfort field study of naturally ventilated classrooms in Kharagpur, India, Building and Environment, 92, 396406, (2015).

[14] Zaki, S.A., Damiati, S.A., Rijal, H.B., Hagishima, A. ve Abd Razak, A., Adaptive thermal comfort in university classrooms in Malaysia and Japan, Building and Environment, 294-306, 122, (2017).

[15] Singh, M.K., Kumar, S., Ooka, R., Rijal, H.B., Gupta, G. ve Kumar, A., Status of thermal comfort in naturally ventilated classrooms during the summer season in the composite climate of India, Building and Environment, 128, 287-304, (2018).

[16] Mustapa, M.S., Zaki, S.A., Rijal, H.B., Hagishima, A. ve Ali, M.S.M., Thermal comfort and occupant adaptive behaviour in Japanese university buildings with free running and cooling mode offices during summer, Building and Environment, 105, 332-342, (2016). 
[17] López-Pérez, L.A., Flores-Prieto, J.J. ve Ríos-Rojas, C., Adaptive thermal comfort model for educational buildings in a hot-humid climate, Building and Environment, 150, 181-194, (2019).

[18] 15251 Indoor environmental input parameters for design and assessment of energy performance of buildings addressing indoor air quality, thermal environment, lighting and acoustics, (2007).

[19] ASHRAE Standard 55: Thermal environmental conditions for human occupancy, (2010).

[20] ISO 7730: Moderate thermal environments - determination of the PMV and PPD indices and specification of the conditions for thermal comfort, (2005).

[21] ANSI/ASHRAE Standard 62.1: Ventilation for acceptable indoor air quality, (2007).

[22] CEN - CR 1752 Ventilation for buildings - design criteria for the indoor environment, (1998).

[23] http://izmir.mgm.gov.tr/FILES/iklim/balikesir_iklim.pdf, (10.08.2020). 